\title{
Social exchange: relations and networks
}

\author{
Jacob Dijkstra ${ }^{1}$
}

Received: 30 March 2015/Revised: 11 September 2015/ Accepted: 18 September 2015/Published online: 6 October 2015

(C) The Author(s) 2015. This article is published with open access at Springerlink.com

\begin{abstract}
In this short paper, I review the literature on social exchange networks, with specific attention to theoretical and experimental research. I indicate how social exchange theory is rooted in general social theory and mention a few of its main links to social network analysis and empirical network research. The paper provides an accessible entry into the literature on social exchange.
\end{abstract}

\section{Introduction}

In this short review paper, I give a synopsis of a special research field within sociology and social psychology: social exchange research. The purpose is to draw the uninitiated reader's attention to this rich field of social inquiry by giving a brief overview of the absolute highlights from it. I will indicate its roots in social theory and especially focus on the experimental branch of research in this tradition. Experimental social exchange research deals with exchange relations and their embeddedness in networks. As such, it is one of the first approaches trying to enrich network analysis with precise and formalized behavioral theory. As I will try to argue, it has important things to say about central concepts from social theory, such as power, trust, and reciprocity.

Jacob Dijkstra

j.dijkstra@rug.nl

1 Department of Sociology, Interuniversity Center for Social Science Theory and Methodology, University of Groningen, Groningen, The Netherlands

\section{Exchange relations and exchange networks}

Social exchange involves the reciprocal transfer of 'goods', both tangible and intangible, such as practical help, advice, information, or prestige. For instance, Homans (1958: 606) states that 'social behavior is an exchange of goods, material goods but also non-material ones, such as the symbols of approval and prestige'. Molm (1997: 12) asserts that 'much of what we need and value in life (e.g., goods, services, companionship, approval, status, information) can only be obtained from others. People depend on one another for such valued resources, and they provide them to one another through the process of exchange'. Finally, Braun (1993: 1) observes that 'exchange of (control over) scarce resources is a fundamental feature of economic and social life. People exchange physical goods, services, time, social approval, respect, attention, courtesies, pleasantries, or favors.'

In the literature, there is little consensus about how economic and social exchange should be distinguished. Instead of making this distinction, most exchange researchers have (implicitly) adopted the meta-theoretical strategy to theory construction, advocated by for instance Wippler and Lindenberg (1987) and Coleman (1990). Thus, theories are proposed about the individual actor in an exchange relation, models are built based upon these theories, and actual human behavior is compared to the predictions of these models. Braun (1993: 2) argues explicitly that this strategy can be applied to social and economic exchange alike when he writes '(...) there is no a priori reason why economic or non-economic exchange and related issues should be consequences of different behavioral principles at the level of individual actors.' Generally then, social exchange relationships can occur whenever two or more actors depend on each other for valuable 
outcomes, and social exchange thus broadly conceived has a long history as an object of social science (e.g., Blau 1964; Ekeh 1974; Homans 1958). The broad conception of exchange renders it widely applicable and social scientists have not desisted stressing this wide scope, as exemplified by the quotes of Homans, Molm, and Braun, above.

More fruitful distinctions than the one between social and economic exchange have been developed. Famously, Molm (1997) classifies exchange according to whether it is reciprocal or negotiated, and whether it is productive, direct, or indirect. Contrary to reciprocal exchange, negotiated exchange is governed by explicit negotiations over the terms of the exchange. In direct exchange, actors $A$ and $B$ directly benefit each other. In indirect exchange, actor B can reciprocate a benefit received from $\mathrm{A}$ by giving to a member of the social system (e.g., C) other than A. In productive exchange, both actors in the relation must contribute for either to benefit. This typology is in accord with the classical distinction between restricted and generalized exchange (e.g., Ekeh 1974), the former resembling negotiated, direct exchange, and the latter reciprocal, indirect exchange.

A landmark in the development of social exchange theory is Emerson's (1962) investigation of power-dependence relations. Emerson (1962: 32) defines the power of A over B as the ' $(\ldots)$ resistance on the part of B which can be potentially overcome by A', and discusses the embeddedness of exchange relationships in the ambient exchange network, in which a connection between two actors indicates an exchange opportunity. Researchers have investigated how personal, cultural and social differentiations underlie exchange network structure (Braun 1993) and what the effects of factors such as uncertainty are on the emerging network structure (Kollock 1994).

Following Emerson's seminal work, experimental social exchange research has focused on the issue of power differences in networks of exchange relationships. In experimental studies, participants exchange resources typically representing a certain monetary value, and power differences are measured as the payoff differences between actors arising from exchange. The majority of experimental studies focus on the distribution of power in static and exogenous networks (but see, Dogan et al. 2009). A milestone in this field is the work of Cook et al. (1983), who show that standard centrality measures badly predict power distributions in exchange networks. The central implication from their research is that to understand power in social networks, one must understand (1) the dyadic social (exchange) processes on the micro-level, and (2) the way dyadic relations are connected to the larger network. Bonacich's centrality measures (1987) were developed as an explicit acknowledgment of this discovery.
The issue of micro-level exchange processes is addressed by several algorithms predicting power distributions across networks (e.g., Bienenstock and Bonacich 1992; Cook and Yamagishi 1992; Friedkin 1992; Willer 1999), many of which are related to cooperative game theory. For instance, the exchange-resistance solution (Willer 1999) is equivalent to the Raiffa-Kalai-Smorodinsky solution (Heckathorn 1980), the core (Bienenstock and Bonacich 1992) is itself a common game theory solution, and the Nash bargaining solution has been extended to exchange networks (Braun and Gautschi 2006). The most salient general outcome of this research is the classification of networks in strong, weak, and equal power structures (e.g., Willer 1999), exhibiting large, small, or no payoff differences between actors in the network, respectively. Different algorithms, however, generally differ in the assignment of networks to the different classes.

Regarding the issue of how exchange relations connect to form a network, two important classifications have been developed. The first is the distinction between positive and negative connection. Two relations are connected positively if exchange in one is contingent on exchange in the other, and negatively if exchange in one is contingent on non-exchange in the other. The second classification distinguishes between exclusive, inclusive, and null connections (Willer 1992). An actor is exclusively connected if she can exchange with fewer than all her potential exchange partners, and if she benefits from each exchange separately. She is inclusively connected if she can exchange with all her potential exchange partners and if she has to complete an exchange with all of them to get any benefit. She is null connected if she can exchange with all her potential exchange partners and if she benefits from each exchange separately. The connection type generally affects the power distribution, with exclusive and negative connections being important sources of power.

The emphasis in experimental exchange network research on the distribution of power across network members has implied a narrowing of the focus of classical exchange theorists, who were typically more concerned with the norms, obligations, trust, and commitment created by social exchanges, rather than with their 'material' outcomes or exact terms of exchange. Within experimental network exchange research, however, there is also a strong tradition in the more classical direction, and it is arguably currently the most vibrant part of exchange research (Molm et al. 2007; Lawler et al. 2008). The most salient single finding from this research is the predominant importance of reciprocal and generalized modes of exchange for the creation of strong and trustful relationships (e.g., Molm et al. 2012). 


\section{Conclusions}

In this short review paper, I have given a very general overview of social exchange network research in sociology and social psychology. In the process, I have left many interesting contributions out, focusing on the absolute highlights of the field. These are not necessarily better than other contributions, but in my opinion they do provide the best entrance into the field for the uninitiated reader. Although I have almost exclusively discussed theoretical and experimental work, social exchange theory is very broad in terms of its potential empirical applications. To name again but a single highlight, consider Uehara's (1990) seminal study of social exchange networks among unemployed women in Chicago. In addition, social exchange theory continues to provide a theoretical basis for social network research (Jackson et al. 2012).

Open Access This article is distributed under the terms of the Creative Commons Attribution 4.0 International License (http://crea tivecommons.org/licenses/by/4.0/), which permits unrestricted use, distribution, and reproduction in any medium, provided you give appropriate credit to the original author(s) and the source, provide a link to the Creative Commons license, and indicate if changes were made.

\section{References}

Bienenstock EJ, Bonacich P (1992) The core as a solution to exclusionary networks. Soc Netw 14:231-243

Blau PM (1964) Exchange and power in social life. Wiley, New York

Bonacich P (1987) Power and centrality: a family of measures. Am J Soc 92(5):1170-1182

Braun N (1993) Socially embedded exchange. Peter Lang, Frankfurt

Braun N, Gautschi T (2006) A nash bargaining model for simple exchange networks. Soc Netw 28(1):1-23

Coleman JS (1990) Foundations of social theory. Harvard University Press, Cambridge

Cook Karen S, Yamagishi Toshio (1992) Power in exchange networks: a power-dependence formulation. Soc Netw $14: 245-265$
Cook KS, Emerson RM, Gillmore MR, Yamagishi T (1983) The distribution of power in exchange networks: theory and experimental results. Am J Soc 89:275-305

Dogan G, van Assen MALM, van de Rijt A, Buskens V (2009) The stability of exchange networks. Soc Netw 31(2):118-125

Ekeh PP (1974) Social exchange theory. Heinemann, London

Emerson RM (1962) Power-dependence relations. Am Soc Rev 27(1):31-41

Emerson RM (1972) Exchange theory, part II: exchange relations and networks. In: Berger J, Zelditch M, Anderson B (eds) Sociological theories in progress, vol 2. Houghton Mifflin, Boston, pp 58-87

Friedkin NE (1992) An expected value model of social power. Predictions for selected exchange networks. Soc Netw 14:213-229

Heckathorn D (1980) A unified model for bargaining and conflict. Behav Sci 25:261-284

Homans GC (1958) Social behavior as exchange. J Am Soc 62:597-606

Jackson MO, Rodriguez-Barraquer T, Tan X (2012) Social capital and social quilts: network patterns of favor exchange. Am Econ Rev 112(5):1857-1897

Kollock P (1994) The emergence of exchange structures: an experimental study of uncertainty, commitment, and trust. Am J Soc 100:313-345

Lawler EJ, Thye SR, Yoon J (2008) Social exchange and micro social order. Am Soc Rev 73:519-542

Molm LD (1997) Coercive power in social exchange. Cambridge University Press, Cambridge

Molm LD, Collet JL, Schaefer DR (2007) Building solidarity through generalized exchange. Am J Soc 113:205-242

Molm LD, Whitham MM, Melamed D (2012) Forms of exchange and integrative bonds: effects of history and embeddedness. Am Soc Rev 77:141-165

Uehara E (1990) Dual exchange theory, social networks, and informal social support. Am J Soc 96(3):512-557

Willer D (1992) Predicting power in exchange networks: a brief history and introduction to the issues. Soc Netw 14(3-4):187-211

Willer D (ed) (1999) Network exchange theory. Praeger Press, Westport

Wippler R, Lindenberg S (1987) Collective phenomena and rational choice. In: Alexander JC, Giesen B, Münch R, Smelser NJ (eds) The micro-macro link. University of California Press, Berkeley, pp 135-152 